\title{
Can a high visceral adiposity index predict female sexual dysfunction in sexually active women? Results of a cross-sectional study.
}

\author{
Ramazan Aşç1 ${ }^{1}$, Mustafa Bolat ${ }^{2}$, Cihad Dündar ${ }^{3}$, Ayse Zehra Ozdemir ${ }^{3}$, and Aysegul \\ Atmaca $^{3}$ \\ ${ }^{1}$ Ondokuz Mayis University Faculty of Medicine \\ ${ }^{2}$ Gazi State Hospital \\ ${ }^{3}$ Ondokuz Mayis University
}

May 12, 2021

\begin{abstract}
Aims: To our knowledge, this is the first study investigating the impact of high visceral adiposity index on female sexual dysfunction (FSD). We aimed to show the impact of increased levels of visceral adiposity index (VAI) on FSD compared to body mass index (BMI) and waist circumference (WC). Methods: We included 158 participants in two groups: Group 1 (n=68 with normal sexual function) and Group 2 ( $\mathrm{n}=90$ with sexual dysfunction). Demographic, clinic data, presence of metabolic syndrome (MeTS) and comorbidities were recorded. The BMI, WC and the visceral adiposity index were calculated. Sexual function was assessed using the female sexual function index (FSFI). Results: The mean age and all the anthropometric variables were similar between the groups $(\mathrm{p}>0.05)$. Metabolic syndrome was associated with lower arousal and lubrication scores than those without metabolic syndrome $(\mathrm{p}=0.023)$. The higher VAI was associated with lower desire, lubrication and orgasm scores $(\mathrm{p}<0.05)$. Each integer increase of the VAI weakly predicted decrease of desire $(\mathrm{p}=0.015)$, arousal $(\mathrm{p}=0.015)$, lubrication $(\mathrm{p}=0.005)$ and satisfaction $(\mathrm{p}=0.046)$. Conclusion: The VAI was linked with lower scores in some female sexual function subdomains, but the correlation coefficient was low, indicating a weak association. Further studies with a higher number of participants are needed to conclude that the VAI may increase the risk of FSD, particularly in patients with metabolic syndrome.
\end{abstract}

Title: Can a high visceral adiposity index predict female sexual dysfunction in sexually active women? Results of a cross-sectional study

\section{Abstract}

Aims: To our knowledge, this is the first study investigating the impact of high visceral adiposity index on female sexual dysfunction (FSD). We aimed to show the impact of increased levels of visceral adiposity index (VAI) on FSD compared to body mass index (BMI) and waist circumference (WC).

Methods: We included 158 participants in two groups: Group 1 ( $\mathrm{n}=68$ with normal sexual function) and Group 2 ( $\mathrm{n}=90$ with sexual dysfunction). Demographic, clinic data, presence of metabolic syndrome (MeTS) and comorbidities were recorded. The BMI, WC and the visceral adiposity index were calculated. Sexual function was assessed using the female sexual function index (FSFI).

Results: The mean age and all the anthropometric variables were similar between the groups ( $\mathrm{p}>0.05)$. Metabolic syndrome was associated with lower arousal and lubrication scores than those without metabolic syndrome $(\mathrm{p}=0.023)$. The higher VAI was associated with lower desire, lubrication and orgasm scores $(\mathrm{p}<0.05)$. Each integer increase of the VAI weakly predicted decrease of desire $(\mathrm{p}=0.015)$, arousal $(\mathrm{p}=0.015)$, lubrication $(\mathrm{p}=0.005)$ and satisfaction $(\mathrm{p}=0.046)$. 
Conclusion: The VAI was linked with lower scores in some female sexual function subdomains, but the correlation coefficient was low, indicating a weak association. Further studies with a higher number of participants are needed to conclude that the VAI may increase the risk of FSD, particularly in patients with metabolic syndrome.

Key Words: Body mass index, female, sexual dysfunction, obesity, visceral adiposity index, waist circumference

\section{What's already known about this topic?}

1. Female sexual dysfunction (FSD) is a considerably underestimated condition, affects almost half of premenopausal sexually active women.

2. Various mediators, including dopamine, norepinephrine, melanocortin, oxytocin, testosterone, estradiol, progesterone, vasoactive intestinal polypeptide, nitric oxide, calcitonin gene-related peptide and neuropeptide-Y play a role in female sexual function.

3. Many factors may contribute to FSD, including obesity, diabetes mellitus, smoking, hyperlipidemia, heart diseases, liver failure, alcoholism, depression, drug abuse or medications.

\section{What does this article add?}

This study is the first to evaluate the impact of visceral adiposity index on different domains of female sexual function compared to body mass index and waist circumference.

\section{INTRODUCTION}

Female sexual dysfunction (FSD) is a considerably underestimated condition, affects $41 \%$ of sexually active women aged 45-64 in the dimensions of sexual desire, arousal, lubrication, orgasm, satisfaction, and pain. ${ }^{1}$ Prevalence for FSD is reported in up to $50 \%$ of women, at least in one dimension, regardless of age. ${ }^{2}$ Oksuz et al. stated that FSD prevalence was $48.3 \%$ in Turkish women, and smoking, older age, menopause and marital status were contributing risk factors. ${ }^{3}$

Distal vagina, urethra and clitoris create the clitoral complex. Clitoris receive (a) somatic fibres (a branch of the pudendal nerve) that supply the skin as the dorsal nerve of the clitoris, and (b) visceral fibres (cavernous nerves) that supply arteries to the erectile tissue. Vascular engorgement and clitoral tumescence are controlled by visceral nerves in the reflex arc and motor fibres that may be augmented or suppressed voluntarily. Sexual desire and arousal are thought to be under the control of parasympathetic and sympathetic arousal with the support of sex hormones and psychological factors. Cortex, limbic hippocampal structures, midbrain central gray, hypothalamic nuclei (the medial preoptic area, ventromedial nucleus, paraventricular nucleus, and anterior hypothalamic region) are the highest centers where the control of sexual arousal is regulated. Dopamine, norepinephrine, melanocortin, oxytocin, testosterone, estradiol and progesterone were central sexual stimulating mediators; serotonin, prolactin and opioids are sexually inhibiting neuromediators ${ }^{4}$ and serotonergic stimulation increases blood flow in the clitoris, bulbs, periurethral erotic tissue and vagina. Testosterone and estradiol also contribute to vasocongestion. ${ }^{5}$ Serotonin reduces genital sensation; sympathetic stimulation decreases genital blood flow. While vasoactive intestinal polypeptide (VIP) and NO are the primary neurotransmitters that provide tumescence by relaxing the clitoral smooth muscles during sexual stimulation; VIP, NO, calcitonin gene-related peptide (CGRP), neuropeptide-Y (NPY) and noradrenaline (NA) are peripheral neurotransmitters involved in vasomotion that provide vaginal transudation. ${ }^{6}$ As a consequence, engorgement of the clitoral complex with sexual stimulus, vulvar swelling occurs, and secretory response is initiated in the distal vagina and urethra. Depending on the increase in blood flow with sexual stimulation, a 2-3 fold increase in size occurs in the labia minora. The labial evertion caused by the increase in size makes vaginal introitus suitable for penile penetration. Non-erectile vascular tissues in the urethral orifice and vaginal wall are also sensitive to sexual stimuli. Sufficient sexual arousal stimulates the Skene (female prostate) and Bartholin's glands, causing an increase in secretion. Sexual function in women is achieved not only by psychological but also by the harmonious interaction of neurochemical and organic 
factors. ${ }^{7}$ Somatic diseases such as diabetes mellitus, spinal cord injury or pelvic surgeries can complicate FSD by causing damage to the blood vessels and nervous system. ${ }^{8}$ Chronic ischemia in female genital tissues causes structural and functional changes leading to decreased arousal and lubrication. ${ }^{9}$

According to the Basson's sexual response cycle, enhancing intimacy or bonding to feel attractive or desired may be motivated to engage in sexual activity, and a state of "sexual neutrality" may result in a sexual experience. ${ }^{10}$ Disruption of at least one of these stages can cause a decrease in desire and lubrication. Except for sexual activity, surfaces of the vagina are covered by a thin film of fluid, preventing friction. However, the amount of fluid is insufficient for painless penile penetration. One of the subdomains of FSD is pain that can be explained by hypersensitivity to pain sensation or a decreased vestibular nociceptor threshold. ${ }^{10}$

Many factors may contribute to FSD, including diabetes mellitus, smoking, hyperlipidemia, heart diseases, liver failure, alcoholism, depression, drug abuse or medications. Diabetes mellitus may provoke an atherosclerotic process that could be a reason for decreased vaginal lubrication. ${ }^{8}$ The FSD associated with obesity is one of the commonly reported etiological factors.

To date, obesity and its impact on various diseases have been studied in many studies using the body mass index (BMI) or waist circumference (WC). ${ }^{12}$ The fact that WC mainly measures subcutaneous tissue and BMI cannot predict body fat homogeneously has led to an increase in scientific studies investigating more reliable markers. ${ }^{13}$ The visceral adiposity index (VAI) measures visceral adiposity. ${ }^{14}$ The VAI was used in many studies as a useful tool. ${ }^{15}$

Conflicting data have been published regarding the impact of metabolic syndrome or obesity without metabolic syndrome on female sexual function. Based on this, we aimed whether the VAI was a good predictor of female sexual dysfunction. To our knowledge, this study is the first to evaluate the impact of visceral adiposity index on different domains of female sexual function compared to body mass index and waist circumference.

\section{PATIENTS AND METHODS}

Following the local ethics board's approval (B.30.2.ODM.0.20.08/501), of the 213 heterosexual sexually active women of reproductive age, 158 were included in the study. Women with the following conditions were excluded from the study: neurological $(n=19)$, psychiatric $(n=9)$, hormonal $(n=17)$, gynecological surgery including bilateral oophorectomy $(n=9)$, and malignant gynecological disease $(n=4)$. Patients were informed about the study, and informed consent was obtained. Sexual function was evaluated using the Turkish-version of the Female Sexual Function Index (FSFI), which consists of 17 questions provided by the Turkish Society of Andrology. According to the FSFI, higher the FSFI scores indicate better sexual functioning that includes 19 questions on six topics, including sexual desire (first two questions), arousal (questions 3 to 6), lubrication (questions 7 to 10), orgasm (questions 11 to 13), satisfaction (questions 14 to 16), and pain (questions 17 to 19). The lowest score is 2, and the highest score is 36 . The total FSFI score under 26.55 was accepted as FSD. ${ }^{16}$ Women with BMI $<25 \mathrm{~kg} / \mathrm{m}^{2}$ were considered healthy weight (BMI-1), those between $25.0-29.9 \mathrm{~kg} / \mathrm{m}^{2}$ were overweight (BMI-2) and those with a BMI greater than 30 $\mathrm{kg} / \mathrm{m}^{2}$ obese (BMI-3). The WC was measured at the level of the umbilicus in $\mathrm{cm}$. The WC lower than 90 $\mathrm{cm}$ was considered healthy (WC-1), and $\mathrm{WC}>90 \mathrm{~cm}$ was considered an obesity-related condition (WC-2). The VAI was calculated using the formula WC / $\left(36.58+(1.89 \times \mathrm{BMI}) \times(\mathrm{TG} / 0.81) \times(1.52 / \mathrm{HDL}) .{ }^{16}\right.$ Regarding the individual domains, a domain score of zero indicates that the respondent reported having no sexual activity. Different "factors" have been created for all domains. The factors for desire, arousal, and lubrication and orgasm, satisfaction and pain are 0.6, 0.3, and 0.4, respectively. Individual scores of the domains were multiplied by the corresponding domain factor. The total FSFI score varies from 2 to 36, and scores equal to or higher than 26.55 show normal female sexuality, and when a respondent's total scale score was below 26.55, FSD is considered. Sixty-eight women with normal sexual function were included in Group 1 group, and 90 women with sexual dysfunction were assigned to Group 2. Age, length, body weight, body mass index (BMI), waist circumference (WC), comorbidities such as hypertension, diabetes and coronary artery disease, hormonal disease, drug use, smoking in pack/year, and alcohol consumption were recorded. 
Serum high-density lipoprotein (HDL) and triglyceride (TG) levels were recorded. Total FSFI measured the sexual function, and individual scores of sexual desire, arousal, lubrication, orgasm, satisfaction and pain subdomains were calculated.

MeTS criteria are described according to the National Cholesterol Education Program. ${ }^{17}$

A waist circumference of greater than $102 \mathrm{~cm}$,

1. Triglyceride level higher than $150 \mathrm{mg} / \mathrm{dL}$, or receiving treatment for hypertriglyceridemia,

2. HDL cholesterol of less than $40 \mathrm{mg} / \mathrm{dL}$,

3. Systolic blood pressure higher than $130 \mathrm{~mm} \mathrm{Hg}$, or diastolic blood pressure higher than $85 \mathrm{~mm} \mathrm{Hg}$, or receiving antihypertensive treatment

4. Fasting glucose level greater than $100 \mathrm{mg} / \mathrm{dL}$, or receiving treatment for hyperglycemia.

\section{Statistical Analysis}

The Statistical package program SPPS v. 15 (2012. IBM SPSS Statistics for Mac, Version 21.0.0.0, Armonk, NY, USA: IBM Corp.) was performed. Numerical variables normally distributed were given as mean \pm SD and categorical variables as frequency $(\%)$. The inter-group differences were determined using the MannWhitney $U$ and Kruskal-Wallis tests for numerical variables. The relationships between the categorical variables were analyzed using Pearson's Chi-square and Fisher's exact tests. The factors including VAI score, BMI and waist circumference affecting the FSFI score as a dependent variable were determined by multivariate logistic regression analysis. A p-value lower than 0.05 was accepted as statistically significant.

\section{RESULTS}

Regardless of the grouping, the mean VAI was 4.45. The mean age, WC, BMI, VAI fasting serum glucose, HDL-cholesterol and TG levels levels were similar between the groups ( $\mathrm{p}>0.05)$ (Table 1). Sensitivity and specificity for the cut-off values of WC $89 \mathrm{~cm}$, BMI $<25,25.0-29.9$ and [?]30.0 kg/m2 and VAI 4.45 were $53.3 \%$ and $54.4 \% ; 18.9 \%$ and $88.2 \%$; and $52.2 \%$ and $48.5 \%$, respectively (Fig. 1). Groups were similar in terms of MeTS, hypertension, diabetes, smoking and alcohol abuse $(\mathrm{p}>0.05)$ (Table 2). The mean total FSFI score and all the subgroups were significantly higher in Group 1 group than Group $2(\mathrm{p}<0.05)$ (Table 3). Participants with MeTS had substantially lower total FSFI scores than those without MeTS ( $\mathrm{p}=0.023)$. Considering the subdomains, arousal and lubrication scores significantly lower in patients with MeTS than without MeTS $(\mathrm{p}<0.05)$, whereas desire, orgasm, satisfaction and pain scores were similar $(\mathrm{p}>0.05)$ (Table 4). For different cut-off levels of WC (WC-1 and WC-2) and BMI (BMI-1, BMI-2 and BMI-3), all the subdomain scores were similar $(\mathrm{p}>0.05)$. Only desire, lubrication and orgasm scores were significantly lower in participants with VAI [?] 4.45 than with VAI $<4.45(\mathrm{p}<0.05)$ (Table 5). Logistic regression analysis showed that each integer increase of VAI weakly predicted decrease of desire $(\mathrm{r}=0.193, \mathrm{p}=0.015)$, arousal $(\mathrm{r}=0.193$, $\mathrm{p}=0.015)$, lubrication $(\mathrm{r}=0.222, \mathrm{p}=0.005)$ and satisfaction $(\mathrm{r}=0.159, \mathrm{p}=0.046)$, but did not predicted orgasm $(\mathrm{r}=0.156, \mathrm{p}=0.050)$ and pain $(\mathrm{r}=0.017, \mathrm{p}=0.830)$ (Table 6).

\section{DISCUSSION}

Sexual dysfunction in women has a multifactorial etiology, including psychosocial factors and the difficulty of marital relationships, but the relationship between sexual function and obesity remains unclear. ${ }^{18}$ Female sexual dysfunction is reported in $40 \%$ of women in the United States. ${ }^{19}$ However, the prevalence of FSD in women of reproductive age may vary due to different geographical and cultural factors. In Turkey, previous studies reported the FSD prevalence between $46.9 \%$ and $53.2 \% .^{20}$

Consistent with these reports, a slightly higher rate of FSD with $56.9 \%$ was reported in this study. Obesity is generally assessed using anthropometric measurements such as WC and BMI. Considering the WC, only several reports investigated the impact of increased WC levels on female sexual function. We recently showed that WC was not a reliable marker for erectile dysfunction in sexually active men. In that report, the WC failed to show the real burden of body fat because it only measures the subcutaneous adipose tissue. ${ }^{21}$ Unlike many studies in men, only a few conflicting reports have been reported investigating the relationship 
between WC and FSD in women. The present study showed that the WC was not a good predictor for all the subdomains of FSD in women with a sensitivity of $53.3 \%$ and specificity of $54.4 \%$, as shown in Fig. 1 and Table $5(\mathrm{OR}=1.019, \mathrm{p}=0.318)$. Data provided by Paningbatan et al. similarly showed that greater WC than 35 inches was not associated with FSD. ${ }^{22}$

Contrary to these reports, Trompeter et al. stated that women with high WC were more sexually inactive than those with low WC. ${ }^{23}$ In another report, the $\mathrm{WC}$ was shown to decrease vaginal orgasm. ${ }^{24}$

In our opinion, only a few studies with limited data have been conducted in the literature showing the relationship between WC and FSD. Therefore, further studies are needed to reach satisfactory results in this regard.

BMI's sensitivity and specificity are low due to individual differences such as age, gender, race, muscle mass, and fluid intake habits. ${ }^{25}$ Our results showed that BMI did not affect the female sexual function index $(\mathrm{OR}=0.983, \mathrm{p}=0.742)$. Conflicting data have been published regarding the BMI and FSD. Some authors reported significant relationships between the BMI and the FSD. ${ }^{26}$

Besides, some authors stated that the BMI affected some of the subdomains of female sexual function. Rabeipoor et al. stated that BMI only affected sexual satisfaction but did not impair sexual function in overweight or obese women. ${ }^{27}$ Another study showed that the BMI impaired arousal, lubrication, orgasm and satisfaction, whereas the desire and pain scores remained stable ${ }^{28}$. However, some authors reported similar FSFI scores between the obese women and an age-matched control group. ${ }^{29}$

When interpreting data on BMI and FSD, one should keep in mind that BMI, as an anthropometric measure, may cause different results in different individuals for various reasons.

Recent reports showed a significant correlation between visceral adiposity index and male sexual function. ${ }^{13}$ Although many disciplines other than andrology carried out numerous studies on VAI, as far as we know, the current study is the first in the English literature investigating the relationship between the FSD and VAI. Studies previously conducted in our clinic showed that each integer increase of VAI in men increased the likelihood of erectile dysfunction by 1.4 times. The VAI, especially in those with metabolic syndrome, was two-fold higher than those without metabolic syndrome. ${ }^{21}$

Considering the VAI level of less than or greater than 4.45; our results showed that arousal, satisfaction and pain scores remained stable, whereas desire, lubrication and orgasm scores were lower (Table 5). Although the VAI scores were similar in both groups, a significant decrease in the arousal, satisfaction and pain scores did not reach a statistical significance in the logistic regression analysis in individuals with higher VAI values regardless of the groups. This study was conducted based on anthropometric (such as WC, BMI, VAI) and biochemical parameters. Besides the low number of participants, one of the reasons the logistic regression analysis could not show the VAI as a risk factor can be attributed to its anthropometric basis. In this context and the psychogenic situation, the lack of consideration of various factors such as parity, number of births, birth type, partner characteristics, comfort during the sexual relationship, and privacy issues can be perceived as limiting factors. Although it may be considered a limiting factor, providing the parameters mentioned above is challenging, especially in populations where sexual privacy is at the forefront. Multiparity was associated with less orgasmic and pain problems compared to nulliparity. ${ }^{30}$ With psychological and biological aspects, childbirth has an essential impact on female sexual function. ${ }^{31}$

Female sexual dysfunctions related to MeTS may be a messenger of severe conditions such as cardiovascular and cerebrovascular diseases. ${ }^{32}$ The relationship between the MeTS and FSD has been studied in several studies. Di Francesco et al. showed that MeTS was associated with a higher prevalence of low sexual desire, orgasm and satisfaction than those without MeTS. ${ }^{33}$ Metabolic syndrome has been reported to cause reduced vaginal engorgement via neuropathy and pelvic vascular injury. ${ }^{34}$ Excessive adipose tissue accumulation is strongly associated with MeTS. As a continuous process, adipogenesis works not only for energy storage but also for immune and endocrine functions. Therefore increased adipogenesis may result in inflammatory, immune and cardiovascular disorders secondary to MeTS. ${ }^{33}$ 
Based on this, it is thought that MeTS may affect female sexual function by disrupting oxygenation by reducing pelvic blood flow through chronic vascular inflammation, oxidative stress and atherosclerosis that can explain the higher rate of FSD in postmenopausal and premenopausal relatively older women. ${ }^{35}$

In the present study, logistic regression analysis showed that the Odds ratio between MeTS and FSD was 2.27 , which could not reach statistical significance $(\mathrm{p}=0.153)$. This finding can be explained by the relatively young patients in this study and the relatively low number of participants (six were in Group 1 group $(8.8 \%$ and 19 were in Group 2 (17.8\%). Unlike other anthropometric variables such as BMI and WC, our opinion is that the significant decrease in desire, lubrication and orgasm scores is remarkable considering the VAI> 4.45. Nevertheless, although the presence of MetS was not reached statistical significance in this study, it may have a higher impact on FSD compared to other possible risk factors in a higher cohort of participants.

\section{Strength \& limitations}

The present is the first investigating the effect of the VAI on female sexual dysfunction in the literature compared to the BMI and WC. A relatively low number of participants, lack of information on parity, education, employment, partner status, income, presence of mood disorders are the limiting factors. Excessively high VAI levels in some participants might affect the results, which may be a limiting factor. Another factor that limits the study is that the participants' psychosocial status was not taken into account.

\section{CONCLUSION}

The VAI was not related to decreased subdomains of the FSFI, it was linked with lower scores in some subdomains of the FSFI, but the correlation coefficient was low, indicating a weak association. Further studies with a high number of participants are needed to conclude that the VAI and metabolic syndrome may increase the risk of FSD.

Conflict of Interest: The authors report no conflicts of interest.

Funding: None.

Data available on request due to privacy/ethical restrictions.

1. McCool, ME, Zuelke A, Theurich MA, Knuettel H, Ricci C, Apfelbacher C. Prevalence of female sexual dysfunction among premenopausal women: a systematic review and meta-analysis of observational studies. Sexual Medicine Reviews. 2016;4:197-212.

2. McCabe MP, Sharlip ID, Lewis R, et al. Incidence and Prevalence of Sexual Dysfunction in Women and Men: A Consensus Statement from the Fourth International Consultation on Sexual Medicine 2015. J Sex Med 2016;13:144e152.

3. Oksuz E, Malhan S. Prevalence and risk factors for female sexual dysfunction in Turkish women. J Urol. 2006;175:654-8.

4. Calabro RS, Cacciola A, Bruschetta D, et al. Neuroanatomy and function of human sexual behavior: A neglected or unknown issue? Brain Behav.2019;9:e1389.

5. Puppo V. Anatomy and physiology of the clitoris, vestibular bulbs, and labia minora with a review of the female orgasm and the prevention of female sexual dysfunction. Clin Anat. 2013;26:134-52.

6. Hoyle, CH, Stones RW, Robson T, Whitley K, Burnstock G. Innervation of vasculature and microvasculature of the human vagina by NOS and neuropeptide-containing nerves. J Anat. 1996;1886:33-44.

7. Basson R. Human sexual response. Handb Clin Neurol. 2015;130:11-18.

8. Levin RJ, Both S, Georgiadis J, et al. The Physiology of Female Sexual Function and the Pathophysiology of Female Sexual Dysfunction (Committee 13A). J Sex Med. 2016;13:733-59.

9. Traish AM, Botchevar E, Kim NN. Biochemical factors modulating female genital sexual arousal physiology. J Sex Med. 2010;7:2925-46.

10. Basson R. The recurrent pain and sexual sequelae of provoked vestibulodynia: a perpetuating cycle. J Sex Med. 2012 Aug;9(8):2077-92.

11. Pichlerova D, Bob P, Zmolikova J, et al. Sexual Dysfunctions in Obese Women Before and After Bariatric Surgery. Med Sci Monit. 2019;25,3108-3114. 
12. Kushner RF. Clinical assessment and management of adult obesity. Circulation. 2012;126:2870-2877.

13. Bolat MS, Kocamanoglu F, Ozbek ML, et al. Can High Visceral Adiposity Index Be a Risk Factor for Sexual Dysfunction in Sexually Active Men? J Sex Med. 2020;17:1926-1933.

14. Amato MC, Giordano C, Galia M, et al. Visceral Adiposity Index: A reliable indicator of visceral fat function associated with cardiometabolic risk. Diabetes Care. 2010;33:920-922.

15. Akdemir AO, Karabakan M, Aktas BK, et al. Visceral adiposity index is useful for evaluating obesity effect on erectile dysfunction. Andrologia. 2019;e13282.

16. Rosen R, Brown C, Heiman J, et al. The Female Sexual Function Index (FSFI): a multidimensional self-report instrument for the assessment of female sexual function. J Sex Marital Ther. 2000;26:191208.

17. Thomas GN, Ho SY, Janus ED, et al. Hong Kong Cardiovascular Risk Factor Prevalence Study Steering Committee. The US National Cholesterol Education Programme Adult Treatment Panel III (NCEP ATP III) prevalence of the metabolic syndrome in a Chinese population. Diabetes Res Clin Pract. 2005;67:251-7.

18. Martins e Silva B, Rego LM, Galvao MA, Florencio TM, Incidence of sexual dysfunction in patients with obesity and overweight. Rev. Col. Bras. Cir. [online]. 2013;40(3):196-202.

19. Clayton AH, Valladares JEM. Female Sexual Dysfunction. Med Clin North Am. 2019;103:681-698.

20. Kılıç, M. Prevalence and risk factors of sexual dysfunction in healthy women in Turkey. Afr Health Sci. 2019;9:2623-2633.

21. Bolat MS, Ozbek ML, Şahin B, et al. Impact of high visceral adiposity index associated with metabolic syndrome on erectile function in sexually active men: Results of a cross-sectional study. J Sex Med. 2021;e14111.

22. Paningbatan J, Aragon J, Landicho-Kanapi MP et al. Prevalence of Sexual Dysfunction and its Associated Factors among Women with Diabetes Mellitus Type 2 at Makati Medical Center Outpatient Department. J ASEAN Fed Endocr Soc.2018;33:165-173.

23. Trompeter SE, Bettencourt R, Barrett-Connor E. Metabolic Syndrome and Sexual Function in Postmenopausal Women. Am J Med. 2016;129:1270-1277.

24. Costa RM, Brody S. Orgasm and women's waist circumference. Eur J Obstet Gynecol Reprod Biol. 2014;182:118-22.

25. Flegal KM, Graubard BI, Williamson DF, et al. Excess deaths associated with underweight, overweight obesity. J Am Med Assoc. 2005;293:1861-1867.

26. Bond DS, Vithiananthan, S, Leahey TM, et al. Prevalence and degree of sexual dysfunction in a sample of women seeking bariatric surgery. Surg Obes Relat Dis. 2017;5:698-704.

27. Rabiepoor S, Khalkhali H, Sadeghi, E. What kind of sexual dysfunction is most common among overweight and obese women in reproductive age? Int J Impot Res. 2017;29: 61-64.

28. Esposito K, Ciotola M, Giugliano F, et al. Association of body weight with sexual function in women. Int J Impot Res. 2007;19:353-357.

29. Yaylali GF, Tekekoglu S, Akin F. Sexual dysfunction in obese and overweight women. Int J Impot Res. 2010;22(4):220-6.

30. Witting K, Santtila P, Alanko K, et al. Female sexual function and its associations with number of children, pregnancy, and relationship satisfaction. J Sex Marital Ther. 2008;34(2):89-106.

31. von Sydow K. Sexuality during pregnancy and after childbirth: a metacontent analysis of 59 studies. J Psychosom Res. 1999;47(1):27-49.

32. McCabe MP, Sharlip ID, Lewis R, et al. Incidence and Prevalence of Sexual Dysfunction in Women and Men: A Consensus Statement from the Fourth International Consultation on Sexual Medicine 2015. J Sex Med. 2016;13(2):144-52.

33. Di Francesco S, Caruso M, Robuffo I, et al. The Impact of Metabolic Syndrome and Its Components on Female Sexual Dysfunction: A Narrative Mini-Review. Curr Urol. 2019;12:57-63.

34. Gragasin FS, Michelakis ED, Hogan A, et al. The neurovascular mechanism of clitoral erection: nitric oxide and cGMP-stimulated activation of BKCa channels. FASEB J, 2004;18:1382-91.

35. Miner M, Esposito K, Guay A, et al. Cardiometabolic risk and female sexual health: the Princeton 
III summary. J Sex Med. 2012;9:641-51; quiz 652.

Table 1. Demographic, anthropometric, and clinical variables

\begin{tabular}{|c|c|c|c|}
\hline Variable & $\begin{array}{l}\text { Group } 1 \text { (Patients } \\
\text { with non-FSD*) } \\
(\mathrm{n}=68)\end{array}$ & $\begin{array}{l}\text { Group } 2 \text { (patients } \\
\text { with FSD) }(\mathrm{n}=90)\end{array}$ & $\mathrm{p}$ \\
\hline $\begin{array}{l}\text { Age (year) (mean } \pm \\
\text { SD) }\end{array}$ & $38.2 \pm 6.1$ & $39.6 \pm 7.5$ & 0.397 \\
\hline $\begin{array}{l}\text { Waist circumference } \\
(\mathbf{c m})(\text { mean } \pm \\
\left.\text { SD }^{* *}\right)\end{array}$ & $85.8 \pm 12.4$ & $88.8 \pm 13.6$ & 0.162 \\
\hline $\begin{array}{l}\text { Body mass index } \\
(\mathrm{kg} / \mathrm{m} 2)(\text { mean } \pm \\
\text { SD) }\end{array}$ & $25.2 \pm 4.8$ & $26.3 \pm 5.1$ & 0.578 \\
\hline $\begin{array}{l}\text { Visceral adiposity } \\
\text { index (mean } \pm S D)\end{array}$ & $5.21 \pm 3.7$ & $5.33 \pm 3.3$ & 0.644 \\
\hline $\begin{array}{l}\text { Female sexual } \\
\text { function index } \\
(\text { mean } \pm \mathrm{SD})\end{array}$ & $19.1 \pm 7.1$ & $30.0 \pm 2.5$ & 0.001 \\
\hline $\begin{array}{l}\text { Fasting serum } \\
\text { glucose }(\mathrm{mg}(\mathrm{dL})\end{array}$ & $93.6 \pm 15.4$ & $99.7 \pm 33.9$ & 0.154 \\
\hline $\begin{array}{l}\text { HDL-cholesterol } \\
(\mathrm{mg} / \mathrm{dL})\end{array}$ & $58.5 \pm 23.4$ & $56.1 \pm 16.8$ & 0.717 \\
\hline $\begin{array}{l}\text { Triglyceride } \\
(\mathrm{mg} / \mathrm{dL})\end{array}$ & $140.5 \pm 78.7$ & $141.5 \pm 70.4$ & 0.382 \\
\hline $\begin{array}{l}\text { *FSD, female sexual } \\
\text { dysfunction, } \\
\text { **Standard } \\
\text { deviation }\end{array}$ & $\begin{array}{l}\text { *FSD, female sexual } \\
\text { dysfunction, } \\
* * \text { Standard } \\
\text { deviation }\end{array}$ & $\begin{array}{l}\text { *FSD, female sexual } \\
\text { dysfunction, } \\
* * \text { Standard } \\
\text { deviation }\end{array}$ & $\begin{array}{l}* \text { FSD, female sexual } \\
\text { dysfunction, } \\
* * \text { Standard } \\
\text { deviation }\end{array}$ \\
\hline
\end{tabular}

Table 2. Relationships between subcategories of the variables

\begin{tabular}{|c|c|c|c|}
\hline Variable & Group $1(n=68)$ & Group $2(n=90)$ & $\mathbf{p}$ \\
\hline $\begin{array}{l}\text { Waist circumference } \\
(\mathrm{n}, \%)<89 \mathrm{~cm}[?] 89 \\
\mathrm{~cm}\end{array}$ & $37(54.4) 31(45.6)$ & $42(46.7) 48(55.3)$ & 0.422 \\
\hline $\begin{array}{l}\text { Body mass index } \\
\left(\mathrm{kg} / \mathrm{m}^{2}\right),(\mathrm{n}, \%) \\
\text { BMI-1 }(<25.0) \text { BMI-2 } \\
(25.0-29.9) \text { BMI-3 ([?] } \\
\text { 30.0) }\end{array}$ & $\begin{array}{l}30(44.1) 30(44.1) 8 \\
(11.8)\end{array}$ & $\begin{array}{l}45(50.0) 28(31.1) 17 \\
(18.9)\end{array}$ & 0.191 \\
\hline $\begin{array}{l}\text { Visceral adiposity } \\
\text { index }(\mathrm{n}, \%)<4.45 \\
{[?] 4.45}\end{array}$ & $33(48.5) 35(51.5)$ & $43(47.8) 47(52.2)$ & 0.12 \\
\hline $\begin{array}{l}\text { Metabolic Syndrome } \\
\text { No Yes }\end{array}$ & $62(91,2) 6(8.8)$ & $74(82.2) 19(17.8)$ & 0.163 \\
\hline $\begin{array}{l}\text { Diabetes Mellitus No } \\
\text { Yes }\end{array}$ & $67(98.5) 1(1.5)$ & $85(94.4) 5(5.6)$ & 0.237 \\
\hline Hypertension No Yes & $62(91,2) 6(8.8)$ & $83(92.2) 7(7.8)$ & 1.000 \\
\hline Smoking No Yes & $44(64.7) 24(35.3)$ & $66(73.3) 24(26.7)$ & 0.295 \\
\hline
\end{tabular}



Alcohol abuse (n, \%)
$9(96.7) 2(3.3)$
$92(94.8) 5(5.2)$
0.707

No Yes

Table 3. The mean score of Female Sexual Function Index (FSFI) and its subdomains by the groups.

\begin{tabular}{llll}
\hline Subdomain & Group $\mathbf{1}(\mathbf{n}=\mathbf{6 8})$ & Group $\mathbf{1}(\mathbf{n}=\mathbf{9 0})$ & $\mathbf{p}$ \\
\hline Desire & $3.95 \pm 0.9$ & $2.83 \pm 1.1$ & $<0.001$ \\
Arousal & $4.64 \pm 0.9$ & $2.82 \pm 1.3$ & $<0.001$ \\
Lubrication & $5.16 \pm 0.8$ & $3.02 \pm 1.5$ & $<0.001$ \\
Orgasm & $5.17 \pm 0.8$ & $2.98 \pm 1.6$ & $<0.001$ \\
Satisfaction & $5.32 \pm 0.7$ & $3.36 \pm 1.7$ & $<0,001$ \\
Pain & $5.41 \pm 0.9$ & $3.33 \pm 1.9$ & $<0.001$ \\
Total FSFI & $29.7 \pm 2.8$ & $18.3 \pm 7.4$ & $<0,001$ \\
\hline
\end{tabular}

Table 4. Female Sexual Function Index (FSFI) and its subdomains according to having or not MetS.

\begin{tabular}{llll}
\hline Subdomain & No MeTS $(\mathbf{n}=\mathbf{1 3 6})$ & MetS $(\mathbf{n}=\mathbf{2 2})$ & $\mathbf{p}$ \\
Desire & $3.39 \pm 1.1$ & $2.82 \pm 1.2$ & 0.062 \\
Arousal & $3.72 \pm 1.4$ & $2.89 \pm 1.7$ & 0.020 \\
Lubrication & $4.05 \pm 1.6$ & $3.22 \pm 1.7$ & 0.023 \\
Orgasm & $4.01 \pm 1.7$ & $3.42 \pm 1.8$ & 0.110 \\
Satisfaction & $4.25 \pm 1.7$ & $3.91 \pm 1.8$ & 0.439 \\
Pain & $4.31 \pm 1.9$ & $3.7 \pm 1.9$ & 0.155 \\
Total FSFI & $23.8 \pm 7.8$ & $19.9 \pm 8.6$ & 0.023 \\
\hline
\end{tabular}

Table 5. Relationships of female sexual function scores with different cut-off values of waist circumference,

Desire

Arousal

Lubrication

Orgasm

Satisfaction

Pain

Table 6. Impact of variables on female sexual dysfunction according to the logistic regression analysis.

\begin{tabular}{llllllllll}
\hline & B & S.E. & Wald & \\
Constant WC BMI VAI MeTS $^{\&}$ & $0.786 .019-.017$ & -.040 .821 & 1.161 & 0.019 & -.017 & -.040 & 0.574 & .459 .995 .109 .552 & 2.045 \\
\hline
\end{tabular}




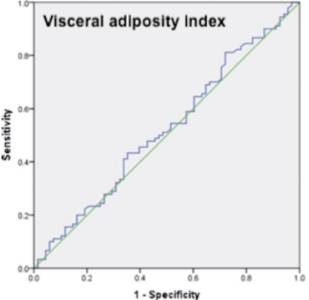

Sensitivity: $52.2 \%$ Specificity: $48.5 \%$

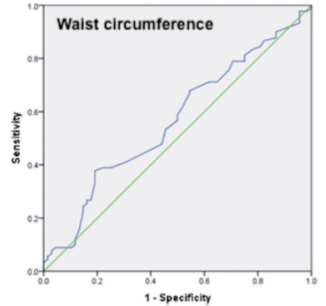

Sensitivity: $53.3 \%$ Specificity: $54.4 \%$

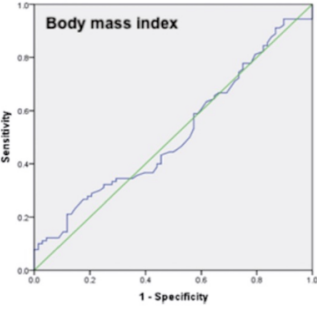

Sensitivity: $18.9 \%$ Specificity: $\mathbf{8 8 . 2 \%}$ 